\title{
High Schottky barrier height of the Al/n-GaAs diodes achieved by sputter deposition
}

\author{
C.-P. Chen and Y. A. Chang \\ University of Wisconsin-Madison, Materials Science and Engineering Department, 1509 University Avenue, \\ Madison, Wisconsin 53706 \\ J.-W. Huang and T. F. Kuech \\ University of Wisconsin-Madison, Chemical Engineering Department, 1415 Johnson Drive, Madison, \\ Wisconsin 53706
}

(Received 21 October 1993; accepted for publication 4 January 1994)

\begin{abstract}
Thermally stable $\mathrm{Al} / n$-GaAs Schottky contacts, up to annealing temperature at $500^{\circ} \mathrm{C}$ for $20 \mathrm{~s}$, have been realized by sputter deposition. The Schottky barrier height was $0.75 \mathrm{eV}(0.9 \mathrm{eV})$ when using the current-voltage $(I-V)$ [capacitance-voltage $(C-V)]$ method with an ideality factor of 1.09 for the as-deposited samples. The Schottky barrier height increased to $0.97 \mathrm{eV}(1.06 \mathrm{eV})$ with an ideality factor of 1.07 after annealing at $400^{\circ} \mathrm{C}$ for $20 \mathrm{~s}$. The discrepancy between $I-V$ and $C-V$ measurements was attributed to deep levels existing in the GaAs substrate. A (200) dark-field cross-section transmission elcctron microscopy image of the contact after annealing at $600{ }^{\circ} \mathrm{C}$ showed that the $(\mathrm{Ga}, \mathrm{Al})$ As phase formed at the interface and the enhancement of the Schottky barrier height was due to the formation of this phase.
\end{abstract}

The electrical and thermal stability of metal GaAs interfaces is a general problem which impacts on many technical areas. The performance and thermal processing stability of GaAs devices can often rely on the interfacial phenomena of metal/GaAs heterostructures. In particular, $\mathrm{Al}$ contacts to $n$-GaAs, which are used extensively as a Schottky barrier gate for metal semiconductor field-effect transistors (MESFETs), have often demonstrated a sensitivity to thermal processing conditions. ${ }^{6}$ Several groups of investigators have tried to make $\mathrm{Al} / n$-GaAs contacts in ultrahigh vacuum to improve the thermal stability of these contacts. ${ }^{1-4}$ Nevertheless, the thermally stable contacts achieved up to date is at $500^{\circ} \mathrm{C}$ annealing for one hour in a conventional furnace. ${ }^{1,2}$ The barrier heights for these as-deposited contacts were about $0.75 \mathrm{eV}$ and for the annealed contacts were less than $0.9 \mathrm{eV}^{1-3}$ The enhancement of the Schottky barrier height (SBH) for the $\mathrm{Al} / n-\mathrm{GaAs}$ diodes has been attributed to the formation of $(\mathrm{Ga}, \mathrm{Al}) \mathrm{As}$ at the $\mathrm{Al} / \mathrm{GaAs}$ interface. However, the formation of $(\mathrm{Ga}, \mathrm{Al})$ As has not yet been directly determincd. This may be due to the difficulty of obtaining the high contrast between $\mathrm{GaAs}$ and $(\mathrm{Ga}, \mathrm{Al}) \mathrm{As}$ using a bright field cross sectional transmission electron microscopy (XTEM) image. In addition, the interfacial reaction between $\mathrm{Al}$ and $\mathrm{GaAs}$ has not been fully explored making predictions of the interfacial structure difficult.

In the present study, the thermally stable contacts refer to Schottky contacts possessing ideality factors less than 1.1 after annealing at $500^{\circ} \mathrm{C}$ for $20 \mathrm{~s}$. Al $/ n$-GaAs has been examined by XTEM, scanning Auger microscopy (SAM), and deep-level transient spectroscopy. The Ga-Al-As ternary phase diagram ${ }^{5}$ was used to rationalize the Schottky enhancement and the interface reaction.

Unintentionally doped $\left(\sim 3 \times 10^{16} \mathrm{~cm}^{-3}\right) n$-GaAs wafers with a (100) orientation were used as substrates in the present study. A lift-off process was used for fabricating the contacts. The substrates were degreased with trichlorethylene (TCE), acetone, and methanol for $5 \mathrm{~min}$ each. The degreased wafers were then patterned with an array of 0.5 -mm-diam dots using a standard lithographic technique. Prior to $\mathrm{Al}$ deposition, the patterned substrates were cleaned for $2 \mathrm{~min}$ in $10 \%$ by volume $\mathrm{NH}_{4} \mathrm{OH}: \mathrm{H}_{2} \mathrm{O}$, followed by blow drying with $\mathrm{N}_{2}$. Al thin films were deposited by sputter deposition to a thickness of $100 \mathrm{~nm}$ at an Ar pressure of $4 \mathrm{~m}$ Torr. Thermal annealing was carried out in a rapid thermal annealing furnace at temperatures ranging from $325^{\circ} \mathrm{C}$ for $5 \mathrm{~min}$ to $600^{\circ} \mathrm{C}$ for $20 \mathrm{~s}$. The back side ohmic contacts were made by alloying In into the GaAs at a temperature of $400{ }^{\circ} \mathrm{C}$ for 1 $\min$.

The $I-V$ characteristics were analyzed using thermionicemission theory. ${ }^{6}$ The relationship between the current and the applied forward voltage is given by the following equation:

$$
\begin{aligned}
I= & S A^{* *} T^{2} \exp \left[-q\left(\phi_{B n}-\Delta \phi_{B n}\right) / k T\right] \\
& \times[\exp (q V / n k T)-1],
\end{aligned}
$$

in which $S$ is the contact area, $A$ is the effective Richardson constant $\left(8.64 \cdot \mathrm{A} / \mathrm{cm}^{2} \mathrm{~K}^{2}\right.$ for $n$-GaAs), $k$ is the Boltzmann constant, $T$ is the temperature in $K, \Delta \phi_{B n}$ is the Schottky barrier lowering $\left[=\left(q E / 4 \pi \epsilon_{S}\right)^{1 / 2},{ }^{6} E\right.$ is the maximum electric field at the metal-semiconductor interface and $\epsilon_{S}$ is the permittivity of semiconductor], and $n$ is the ideality factor. The ideality factor must be close to 1 to assure that thermionic emission is the dominant transport mechanism. The relationship between the rectifier capacitance at the metalsemiconductor interface and the Schottky barrier height used in this study is given by ${ }^{6}$

$$
1 / C^{2}=2\left(\phi_{B n}-V-k T / q\right) / q \epsilon_{S} N_{D},
$$

where $N_{D}$ is the dopant concentration in the semiconductor, $\epsilon_{S}$ is the permittivity of the semiconductor, $C$ is the diode capacitance per unit area, and $V$ is the applied reverse voltage.

The deep-level transient spectroscopy (DLTS) system was carried out to analyze these Schottky diodes. The mea- 
TABLE I. Schottky barrier heights measured by $I-V$ and $C-V$ methods and the ideality factors for the $\mathrm{Al} / n-\mathrm{GaAs}$ contacts are shown as a function of annealing condition.

\begin{tabular}{cllc}
\hline \hline Annealing treatment & $\phi_{B n}^{L . V}$ & $\phi_{B n}^{C-V}$ & $n$ \\
\hline As-deposited & 0.75 & 0.90 & 1.09 \\
$325^{\circ} \mathrm{C} / 5$ min & 0.92 & 1.05 & 1.06 \\
$400^{\circ} \mathrm{C} / 1 \mathrm{~min}$ & 0.97 & 1.06 & 1.07 \\
$500^{\circ} \mathrm{C} / 20 \mathrm{~s}$ & 0.89 & 1.02 & 1.09 \\
\hline
\end{tabular}

surement temperature range was $77-400 \mathrm{~K}$. Four rate windows were monitored simultaneously on the measured transient. These measurements were then used to determine the emission rate, energy levels, and trap concentrations.

$I-V$ measurements show that in linear relationships of $\log I-V$ exist in the forward bias over a wide range of the current measured, i.e., seven orders of magnitude. The leakage current is below $2 \times 10^{-8} \mathrm{~A} / \mathrm{cm}^{2}$ at reverse bias for $1 \mathrm{~V}$ for the contacts annealed at 325 and $400{ }^{\circ} \mathrm{C}$. Linear relationships also exist between $1 / C^{2}$ and the reverse bias. Values of the Schottky barriers, $\phi_{B n}^{I-V}$ and $\phi_{B n}^{C-V}$, as well as the ideality factors, $n$, are summarized in Table I as a function of the annealing temperature. The data clearly indicate the $\mathrm{Al} / n$ GaAs contacts are thermally stable up to $500^{\circ} \mathrm{C}$ annealing for $20 \mathrm{~s}$, similar to those fabricated in ultrahigh vacuum. ${ }^{1,2}$ The contacts, which become non-rectifying after annealed at $600^{\circ} \mathrm{C}$ for $20 \mathrm{~s}$, are not listed in Table I. It is worth noting that the barrier height of the as-deposited contact is the same as that of the epitaxial $\mathrm{Al}$ contact $(0.75 \mathrm{eV})$ on $n$-GaAs, grown by molecular beam epitaxy (MBE). ${ }^{1}$ The high SBH of $0.97 \mathrm{eV}(1.06 \mathrm{eV})$, with an ideality factor 1.07 , when using the $I-V(C-V)$ method occurred for the contacts annealing at $400^{\circ} \mathrm{C}$ for $1 \mathrm{~min}$. The value of $0.97 \mathrm{eV}$ is the highest barrier height achieved so far for the annealed $\mathrm{Al} / n$-GaAs diodes and is close to that of the as-deposited Al/AlAs diodes $(0.93-0.99 \mathrm{eV}){ }^{4,7}$

The Schottky enhancement and the interface reaction can be rationalized in terms of the Ga-Al-As ternary phase diagram. ${ }^{5}$ The compound semiconductors GaAs and AIAs form a series of continuous solid solutions but $\mathrm{Ga}$ and $\mathrm{Al}$ form a two-phase equilibrium. Aluminum, which has an appreciable solubility for $\mathrm{Ga}$, is not in thermodynamic equilibrium with $\mathrm{GaAs}$, but is in equilibrium $(\mathrm{Al}, \mathrm{Ga})$ As. A reaction would occur at the interface when $\mathrm{Al}$ is in contact with $\mathrm{GaAs}$ at a sufficient high temperature. This reaction causes an exchange of $\mathrm{Ga}$ for $\mathrm{Al}$ in the $\mathrm{GaAs}$ substrate as discussed previously, ${ }^{8}$ forming an $\mathrm{Al}$-rich $(\mathrm{Ga}, \mathrm{Al})$ As solid solution at the interface. It is the presence of the Al-rich compound semiconductor at the interface which may cause the Schottky enhancement. A bright-field and a (200) dark-field XTEM images of an $\mathrm{Al} / n$-GaAs contact under $600{ }^{\circ} \mathrm{C}$ annealing are shown in Figs. 1(a) and 1(b). As shown in Fig. 1(a), it is difficult to unambiguously determine the presence of the $(\mathrm{Ga}, \mathrm{Al}) \mathrm{As}$ phase due to the poor contrast between $\mathrm{GaAs}$ and (Ga,Al)As. However, the $(\mathrm{Ga}, \mathrm{Al})$ As phase can be distinguished from the GaAs phase using a (200) dark-field XTEM image. ${ }^{9}$ The difference between the diffraction factor of $\mathrm{Al}$ and that of As is substantial, while the difference between the diffraction factor of $\mathrm{Ga}$ and that of As is quite small. The
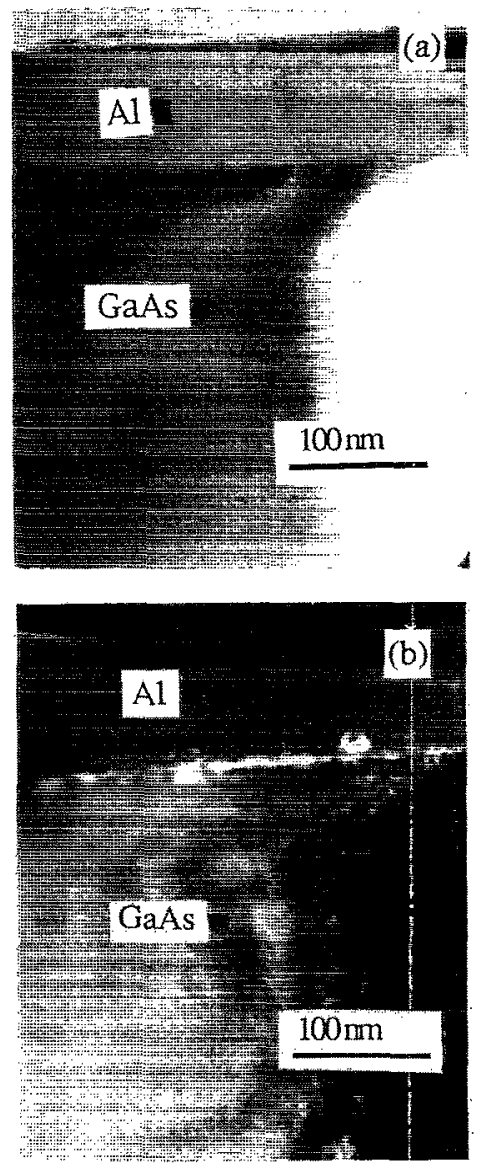

FIG. 1. (a) A bright field and (b) a (200) dark-field XTEM image of the contact annealed at $600^{\circ} \mathrm{C}$ for $20 \mathrm{~s}$, are used to discern the presence of a $(\mathrm{Ga}, \mathrm{Al}) \mathrm{As}$ phase. The $(\mathrm{Ga}, \mathrm{Al}) \mathrm{As}$ phase would be bright and the $\mathrm{GaAs}$ phase would be dark on this dark field image.

(Ga,Al)As phase would be bright and the GaAs phase would be dark on this dark-field image. As shown in Fig. 1(b), a thin bright stripe at the interface can be seen in this image which is assumed to be the $(\mathrm{Ga}, \mathrm{Al})$ As phase. Evidence for the $\mathrm{Ga}-\mathrm{Al}$ exchange reaction leading to the $(\mathrm{Ga}, \mathrm{Al})$ As formation may be found from the Auger depth profiles of the $\mathrm{Al} / n$-GaAs contacts after annealing at $500^{\circ} \mathrm{C}$ for $20 \mathrm{~s}$ shown in Fig. 2. As shown in Fig. 2, the Ga curve lies above the As

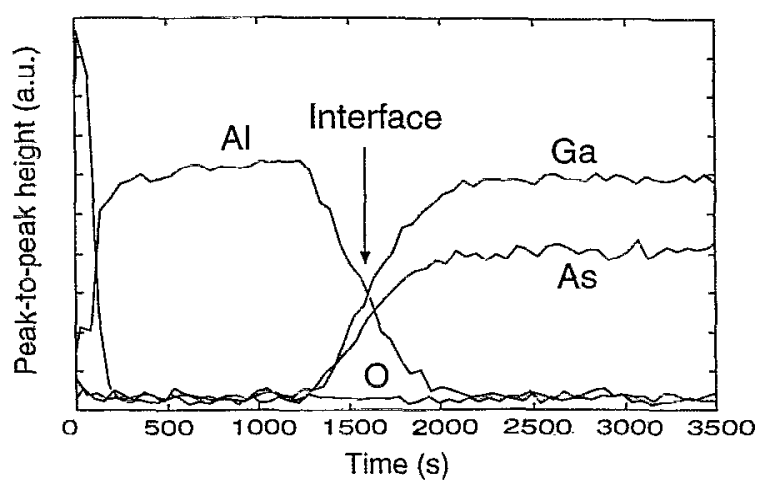

FIG. 2. Auger depth profiles of $\mathrm{Al} / \mathrm{GaAs}$ contacts for samples annealed at $500^{\circ} \mathrm{C}$ for $20 \mathrm{~s}$ indicates the extent of interaction upon annealing. 
curve at the interface (as marked by the arrow). The Ga curve is superimposed on the As curve at the interface for the as-deposited contact which is not shown here. Figure 2 demonstrates that $\mathrm{Ga}$ out-diffused in the $\mathrm{Al}$ thin film and the Ga-Al exchange reaction occurred at the interface.

The appearance of a high barrier height, obtained in the present study but not by other investigators, may be attributed to a difference in the thermal annealing processes used in previous studies. ${ }^{1,2}$ The rapid thermal annealing process, which could limit the extent of interdiffusion at the interface, was used in the current research. Most reaction rates are exponential function of temperature. The extent of reaction at the interface is expected to be more extensive at $500^{\circ} \mathrm{C}$ than that at $400^{\circ} \mathrm{C}$. This extensive reaction, which induces severe out-diffusion of $\mathrm{Ga}$ from GaAs or the indiffusion of Al from the Al layer, can create point and extended defects either at the interface or within the bulk of GaAs. These defects enhance the current transport resulting in a low deduced barrier height when applying Eq. (1). Such additional defect-related current transport would result in a lower barrier height for samples annealed at $500^{\circ} \mathrm{C}$ than those annealed at the $400^{\circ} \mathrm{C}$. The interfacial reaction would be even more severe at $600^{\circ} \mathrm{C}$, generating more defects, since the high annealing temperature is close to the melting point of aluminum $\left(660^{\circ} \mathrm{C}\right)$ leading to an accelerated interfacial reaction. The degradation of the contacts annealed at $600{ }^{\circ} \mathrm{C}$, results from this enhanced reaction. The conventional annealing furnaces with longer annealing times used in previous studies ${ }^{1,2}$ would cause more extensive reactions than the rapid thermal annealing furnaces used in this study. The low Schottky barrier heights, less than $0.9 \mathrm{eV}$, obtained by other groups could be due to more extensive interfacial reactions realized with longer annealing times.

The discrepancy between $\phi_{B n}^{I-V}$ and $\phi_{B n}^{C-V}$ has also been reported in the literature ${ }^{10}$ and has been attributed to several effects. ${ }^{11}$ Three of these effects are possible for the discrepancy in the present study. The first factor is the variation of effective surface area with the reverse bias. The second factor is the surface charges associated with an interfacial oxide layer. The third factor could be deep traps within the bulk of GaAs. The first factor can be ruled out since a planar interface is formed, as seen in the XTEM image in Fig. 1, between $\mathrm{Al}$ and $\mathrm{GaAs}$ for the sample annealed at $600^{\circ} \mathrm{C}$. The second factor becomes significant only when the interfacial oxide layer is very thick. A thick oxide layer $(\sim 3 \mathrm{~nm})$ would result in an ideality factor greater than $1.3 .^{12}$ The second factor is also not significant, because ideal $I-V$ characteristics were obtained in this case. The third factor, enhanced current transport due to deep levels, was explored using DLTS in the present study. Three kinds of deep traps were found in the bulk GaAs substrates for all the as-deposited and annealed diodes. The energy levels are $0.33,0.58$, and $0.78 \mathrm{eV}$ and their concentrations for the as-deposited diode are $3.4 \times 10^{15}, 1.2 \times 10^{14}$, and $8.6 \times 10^{14} \mathrm{~cm}^{-3}$, respectively. Their concentrations for the diode annealed at $400^{\circ} \mathrm{C}$ for a minute are $2.6 \times 10^{15}, 9.3 \times 10^{13}$, and $1.5 \times 10^{15} \mathrm{~cm}^{-3}$, respectively. It seems that the heat treatment, done by rapid thermal annealing process, did not affect the defect structure near the depletion region edge, $\sim 200 \mathrm{~nm}$ from the interface. Similar
DLTS spectra with almost the same energy levels have been observed by other workers and these energy levels were identified as EL6, EL3, and EL2, respectively. ${ }^{13}$ It is worth noting that a high defect concentration which may be induced after annealing at high temperatures resulting in the lowered barrier height cannot be detected by DLTS. DLTS has little sensitivity to deep levels near the metal/GaAs interface. A higher concentration of deep levels would be expected in the GaAs close to the reactive interface. The lower level of defect measured to the depletion region edge, $\sim 200$ $\mathrm{nm}$ from the interface, could reflect the deep level structure near the reaction front. As seen from Fig. 1(b), the reacted layer of $(\mathrm{Ga}, \mathrm{Al}) \mathrm{As}$ is very thin, less than $5 \mathrm{~nm}$ for after the contact annealed at $600^{\circ} \mathrm{C}$ for $20 \mathrm{~s}$. The interfacial reactions may induce a high defect concentration near the interface that cannot be detected by DLTS, yet can result in a reduced barrier height by $I-V$ and a larger flat-band voltage when measured by $C-V,{ }^{16}$ If the distribution of the deep trap concentration was assumed to follow an error function with surface concentration equal to $2.8 \times 10^{20} \mathrm{~cm}^{-3}$, the flat-band voltage can be increased by as much as $0.1 \mathrm{eV}$, leading to different barrier heights determined by $C-V$ and by $I-V$ techniques.

In summary, thermally stable $\mathrm{Al} / n$-GaAs Schottky contacts, up to $500^{\circ} \mathrm{C}$ for $20 \mathrm{~s}$, have becn realized by sputter deposition from an $\mathrm{Al}$ target to (100) $n$-GaAs at a base pressure $\sim 2 \times 10^{-7}$ Torr. The high Schottky barrier height 0.97 $\mathrm{eV}(1.06 \mathrm{eV})$ with an ideality factor 1.07 when using the $I-V$ $(C-V)$ method was measured for the contacts annealed at $400^{\circ} \mathrm{C}$ for $1 \mathrm{~min}$. The value of $0.97 \mathrm{eV}$ is the highest barrier height achieved so far for the $\mathrm{Al} / n$-GaAs diodes. The enhancement of the barrier height for the annealed contacts was rationalized using a $\mathrm{Al}-\mathrm{Ga}$-As ternary phase diagram.

The financial support of the Department of Energy through Grant No. DE-FG02-86ER452754 is gratefully acknowledged.

${ }^{1}$ M. Missous, E. H. Rhoderick, and K. E. Singer, J. Appl. Phys. 59, 3189 (1986)

"N. M. Johnson, T. J. Magee, and J. Peng, J. Vac. Sci. Technol. 13, 838 (1976).

${ }^{3}$ S P. Svensson, G. Landgren, and T. G. Andersson, J. Appl. Phys. 54, 4474 (1983).

${ }^{4}$ W. I. Wang, J. Vac. Sci. Technol. B 1, 574 (1983).

${ }^{5}$ M. B. Panish and S. J. Sumski, J. Phys. Chem. Solids 30, 129 (1969).

${ }^{6}$ S. M. Sze, in Physics of Semiconductor Devices (Wiley, New York, 1981).

${ }^{7}$ P. Revva, J. M. Langer, M. Missous, and A. R. Peaker, J. Appl. Phys. 74, 416 (1993).

${ }^{8}$ Y. A. Chang, Mater. Res. Soc. Symp. 260, 43 (1992).

${ }^{9}$ T. S. Huang, J. G. Peng, and C. C. Lin, J. Vac. Sci. Technol. B 11, 756 (1993).

${ }^{10}$ T. Okumura and K. N. Tu, J. Appl. Phys. 61, 2955 (1987).

${ }^{11}$ A. M. Goodman, J. Appl. Phys. 34, 329 (1963).

${ }^{12}$ E. H. Rhoderick and R. H. Williams, in Metal-Semiconductor Contacts (Clarendon, Oxford, 1988).

${ }^{13}$ L. M. Thomas and V. K. Lakdawala, J. Electron. Mater. 22, 341 (1993). 